\title{
AS COMPETÊNCIAS SOCIOAFETIVAS ACEITAÇÃO E HONRADEZ SEGUNDO A PERCEPÇÃO DE TUTORES A DISTÂNCIA
}

\section{(THE ROLE OF SOCIO-AFFECTIVE COMPETENCE, ACCEPTANCE, AND ETHICS OF ON-LINE TUTORS)}

\author{
Noélia Teixeira Mendes \\ Rede pública municipal de Queimados, Brasil
}

Norma Alves de Sales Santos

Secretaria municipal de educação do Rio de Janeiro, Brasil

Thaís Tenório

Pontifícia Universidade Católica do Rio de Janeiro (PUCRio), Brasil

André Tenório

Instituto Federal de Educação, Ciência e Tecnologia do Rio de Janeiro (IFRJ), Brasil

\section{RESUMO}

O emprego das competências socioafetivas aceitação e honradez na prática pedagógica do tutor a distância foi investigado. A pesquisa analisou as percepções de tutores de cursos de graduação de uma instituição privada de ensino localizada no estado do Rio de Janeiro (Brasil). Todos os tutores reconheceram o significado das competências conforme os preceitos da educação a distância. Diversas situações onde empregar a aceitação e a honradez foram corretamente apontadas pela maioria. Para dois pesquisados, a aceitação seria a principal competência socioafetiva a se exigir de um tutor a distância. $\mathrm{Na}$ opinião unânime dos participantes, a diversidade cultural e intelectual de um grupo de estudantes favoreceria a aprendizagem coletiva e estimularia o desenvolvimento da capacidade de aceitação e o respeito mútuo de cursistas e tutor. Ainda assim, a falta de aceitação seria mais frequente na relação entre cursistas do que com o tutor. Por outro lado, situações problemáticas de agressividade ou presunção de cursistas ou como questionamentos à competência técnica do tutor, para a maioria dos pesquisados, poderiam ser evitadas, ou mesmo contornadas, com atitudes honradas do tutor. Para todos, seria dever do tutor, por meio das competências socioafetivas, construir a parceria e conquistar a confiança do aluno da educação a distância.

Palavraschave: educação a distância, competência socioafetiva, honradez, aceitação. 


\begin{abstract}
In this study, we examine the role of socio-affective competences, acceptance and ethics in the pedagogical practices of on-line tutors. The research surveyed and analyzed the perceptions of graduate course tutors at a private Higher Education Institution in the metropolitan area of Rio de Janeiro (Brazil). All the tutors interviewed recognized the meaning of the different competences according to the general precepts of distance education. Specific situations involving acceptance and honesty were correctly identified by the majority of participants in the study. For two of the researchers, however, acceptance was the main socio-affective competence required by an on-line tutor. Most of the participants who valued cultural and intellectual diversity over the other competences believed that collective learning would stimulate the development of acceptance and mutual respect between students and tutors. Notwithstanding, a lack of acceptance was observed more frequently between students themselves than between students and their tutors. On the other hand, problematic situations were characterized by aggression or by the presumptuousness of students, as well as by the doubting of the technical abilities of the tutor. Such barriers could be prevented or be overcome in cases where the tutor possessed a range of personal ethics. It was generally agreed that it was the duty of the tutor to develop as well as to win the trust of distance education students through socio-affective competences.
\end{abstract}

Keywords: distance education, socio-affective competences, personal honor, honesty, and acceptance.

A educação a distância (EaD) é uma modalidade cada vez mais presente nas instituições de ensino (Neder, 2000). Ela foi favorecida nos últimos anos por inúmeros fatores entre os quais as novas tecnologias de informação e comunicação (nTICs), especialmente, os ambientes virtuais de aprendizagem (AVAs) (Campos, Costa e Santos, 2007; Correia e Santos, 2013; Coutinho, Lisbôa e Bottentuit Jr., 2009; Farias, 2013; Rosa, 2013).

As novas estratégias e recursos não dispensam, contudo, a existência de um profissional de ensino para acompanhar, mediar e incentivar o processo ensinoaprendizagem (Bernardino, 2011; Masetto e Behrens, 2000). Ao contrário, exige um educador mais ativo e participativo (Perrenoud, 200o; Xavier e Silva, 2009).

A “teleducação", por exemplo, não dispensa o professor, embora agregue a seu perfil outras exigências cruciais, como saber lidar com materiais didáticos produzidos com meios eletrônicos, trabalhar em ambientes diferentes daqueles formais da escola ou da universidade, acompanhar ritmos pessoais, conviver com sistemáticas diversificadas de avaliação (Demo, 1996, p. 200).

No contexto da aprendizagem a distância, emerge o tutor (Bernardino, 2011). Ele constrói com o aluno, o lugar, o momento e a forma pela qual se constituirão como sujeitos ativos do processo ensinoaprendizagem (Santos, 2013). Além de promover 
a inter-relação entre saberes científicos, tecnológicos, didático-pedagógicos e cotidianos (Giannella, Struchiner e Ricciardi, 2013).

O tutor deve ser compreendido como um dos sujeitos que participa ativamente da prática pedagógica. Suas atividades desenvolvidas a distância e/ou presencialmente devem contribuir para o desenvolvimento dos processos de ensino e de aprendizagem e para o acompanhamento e avaliação do projeto pedagógico (Brasil, 2007, p. 21).

Esse profissional de $\mathrm{EaD}$ precisa reunir em sua prática um conjunto de saberes que o habilite à mediação de várias disciplinas em ambientes informatizados (Laguardia, Machado e Coutinho, 2010; Moraes, 2011; Nobre e Melo, 2011), o que o leva a assumir um papel multifuncional.

[...] despender energia e tempo e dispor das competências profissionais necessárias para imaginar e criar outros tipos de situações de aprendizagem, que as didáticas contemporâneas encaram como situações amplas, abertas, carregadas de sentido e de regulação, as quais requerem um método de pesquisa, de identificação e de resolução de problemas (Perrenoud, 2000, p. 25).

Ele ainda deve ser capaz de promover a busca da autonomia intelectual pelo aluno ao estimular a capacidade de refletir, resolver problemas, se comunicar, trabalhar em equipe e se adaptar às mudanças (Bernardino, 2011). "O tutor, respeitando a autonomia da aprendizagem de cada cursista estará constantemente orientando, dirigindo e supervisionando o processo de ensino-aprendizagem [...]. É por intermédio dele, também, que se garantirá a efetivação em todos os níveis" (Preti, 1996, p. 27).

Entretanto a autonomia da aprendizagem não deve ser confundida com o abandono do aluno. O tutor precisa velar pelo aprendizado do educando e averiguar sempre seu desenvolvimento nas atividades sejam colaborativas ou individuais.

A atuação ativa na construção do conhecimento requer do tutor competências gerenciais, técnicas, tecnológicas, cognitivas e afetivas (Bernardino, 2011; García Aretio, 2002; Oliveira, 2008; Perrenoud, 1999; Tardif, 2002). Apesar da última não estar estritamente ligada à transmissão do saber, ela possui destaque na assimilação do conhecimento.

[...] podemos definir a afetividade como o domínio funcional que apresenta diferentes manifestações que irão se complexificando ao longo do desenvolvimento e que emergem de uma base eminentemente orgânica até alcançarem relações dinâmicas com a cognição, como pode ser visto nos sentimentos (Ferreira e Acioly-Régnier, 2010, p. 26). 
Competência socioafetiva é a capacidade de relacionamento com a finalidade de envolver e incentivar o cursista no processo ensino-aprendizagem através da afetividade (García Aretio, 2002). Tal habilidade propicia uma atmosfera favorável ao ensino e à aprendizagem no AVA por torná-lo mais prazeroso e humanizado.

$\mathrm{Na}$ tutoria humanizada, o tutor observa as competências socioafetivas em sua atuação ao planejar atividades em busca da criação de um ambiente estimulante envolvendo aspectos interpessoais, criatividade, dialogicidade e socialização (Castillo Arredondo, 1994).

[...] esta figura que lida diretamente com o estudante, seja para prestar esclarecimentos administrativos, seja no processo de ensino e aprendizagem, na avaliação do processo formativo do estudante ou, simplesmente, na monitoria das atividades dos estudantes. Por isso, é considerado o "fator humanizador" do sistema de educação na modalidade a distância (Oliveira, 2008, p. 30).

Não obstante estudos (Bernardino, 2011; Farias, 2010; Giannella, Struchiner e Ricciardi, 2013; Moraes, 2011; Oliveira, 2009; Perrenoud, 2000; Santos, 2013) exponham diversas características essenciais ao tutor, quatro parecem se repetir segundo García Aretio (1994, 2002): cordialidade, capacidade de aceitação, honradez e empatia.

[...] apesar de uma variedade de estudos que descrevem as qualidades de tutores em um curso de EaD, quatro qualidades principais parecem se repetir. São elas: cordialidade, capacidade de aceitação, honradez e empatia. [...] se pode encontrar o tutor ideal, se forem somadas às quatro qualidades descritas a possibilidade de uma escuta e leitura ativa e inteligente. Por leitura e escuta ativa pode-se compreender a atitude de interesse no que é dito (García Aretio, 1994, p. 313).

É indispensável conhecer a atuação tutorial requerida para promover um ambiente prazeroso de aprendizagem colaborativa, onde haja a ajuda solidária entre os participantes embasada na aceitação, cordialidade, empatia e honradez.

\section{As competências socioafetivas aceitação e honradez na EaD}

Entre as competências socioafetivas destacadas (García Aretio, 2002), alguns autores citam a aceitação como a mais importante para a humanização do ensino a distância (Castillo Arredondo, 1994; Oliveira, 2009; Venâncio e Macedo, 2012). "Um educador apaixonado comunica, além de saberes, energia, movendo instâncias profundas naqueles com quem trabalha. Ao mesmo tempo, cria o clima de receptividade e aconchego que amplia e consolida a qualidade positiva das interações" (Oliveira, 2006, p. 58). 
$\mathrm{Na} \mathrm{EaD}$, o tutor deve procurar compreender e aceitar o contexto do aluno de acordo com sua diversidade, além de preservar a crença irrefragável na origem comum como motivação para união de indivíduos diferentes em busca da aprendizagem. Isso implica cumplicidade, colaboração, interação e parceria, essenciais na intervenção pedagógica (Oliveira, 2009).

A tutoria exerce suas funções também no âmbito do afetivo, das atitudes e emoções. Sua ação deve se dar no sentido de observar as diferenças individuais, conhecer e estimular o aluno para que se identifique e se integre ao curso, evitando a ansiedade e a solidão. São essenciais também a comunicação individual, as demonstrações de aceitação e compreensão, o trabalho com as dificuldades, a consciência de que ambos são “aprendentes" e "ensinantes" nesse processo interativo (Oliveira, 2009, p. 13).

Segundo García Aretio (2002), a tutoria pautada na aceitação compreende a realidade do estudante e o faz sentir participante ativo do processo ensinoaprendizagem, "a capacidade de aceitação se relaciona a realidade do aluno, mantendo-o satisfeito com o atendimento que recebe do tutor" (Fiuza, 2002, p. 61).

Tal competência, necessária também à educação presencial, perpetua a capacidade de ouvir e respeitar o outro, apesar das diferenças (Freire, 1995, 2005), além de compreender e aceitar os limites e as dificuldades de cada um. "[...] o professor que é capaz de uma aceitação calorosa, que pode ter uma aceitação positiva incondicional [...] terá feito muitíssimo para estabelecer as condições de aprendizagem" (Venâncio e Macedo, 2012, p. 3).

O desenvolvimento do processo ensino-aprendizagem na $\mathrm{EaD}$ é embasado no diálogo, no debate, no confronto, na atividade coletiva, na discussão de pontos de vista e, principalmente, no respeito mútuo à diversidade (Santos, 2013).

A aceitação nas relações tutor-aluno e aluno-aluno ocorridas em um AVA requer o entendimento da diversidade cultural, social e individual. As diferenças não devem ser um empecilho ao ensinoaprendizagem, por isso os alunos devem ser estimulados a aceitarem as características individuais dos participantes de um grupo de estudo (Nobre e Melo, 2011). Isso requer do tutor trabalhar com a heterogeneidade de modo a contribuir para o aprendizado e crescimento coletivo ao priorizar o respeito entre os participantes (Farias, 2010), afinal "[...] a educação acontece na presença do pluralismo cultural” (Freire, 1994, p. 156).

Embora a importância da aceitação na EaD seja inegável, a honradez também deve ser exercitada simultaneamente na tutoria. Segundo García Aretio (2002), ela pressupõe atitudes verdadeiras e autênticas nas ações pedagógicas. 
$\mathrm{Na} \mathrm{EaD}$, o tutor não deve se comportar como detentor do saber perante os alunos, nem ter tal concepção, pois isso pode criar um afastamento entre o tutor e o estudante e pouca interação no AVA, além de falsas expectativas e, até, evasão (Andrade, 2007). Ao contrário, a postura de mediador da aprendizagem deve ser adotada na tutoria honrada e o educador pode reconhecer não saber determinado assunto e a necessidade de estudá-lo para uma melhor discussão (Andrade, 2007).

Isso pode consolidar nos alunos a distância a sensação de segurança em relação ao curso na medida que se propõe uma relação afetiva de confiança e honestidade. Optar sempre pela verdade e estabelecer relações amistosas pode propiciar ações discentes de criatividade e de liberdade no exercício das atividades propostas.

Uma postura pautada na honradez abrange também a humildade ao reconhecer um erro cometido, a retificação do equívoco e, se for o caso, um pedido de desculpas.

O tutor ao agir com seriedade, responsabilidade e comprometimento embasado nos preceitos das competências socioafetivas busca sempre alcançar os objetivos propostos pelo curso ao promover a união e o empenho entre os cursistas com a finalidade de alcançar uma educação crítica.

Este artigo visou analisar as competências socioafetivas aceitação e honradez na tutoria em ambientes informatizados de ensino-aprendizagem. Com destaque a importância delas na ação cotidiana do trabalho do tutor da EaD ao considerar a conexão do exercício diário da atividade à complexidade das relações humanas.

\section{METODOLOGIA}

O estudo investigou, segundo a visão de um grupo de tutores, a relevância das competências socioafetivas capacidade de aceitação e honradez e seus momentos de aplicação no AVA. Foram analisadas as percepções sobre a aceitação e a honradez, seu uso consciente nas disciplinas a distância e situações problemáticas passíveis de serem contornadas pelo emprego efetivo delas.

A pesquisa teve caráter qualitativo. As percepções de seis tutores a distância que atuavam por meio de um AVA em cursos de graduação foram analisadas. Eles responderam individualmente a um questionário de perguntas abertas e fechadas, aplicado pelos pesquisadores.

A coleta de dados ocorreu em uma universidade particular localizada no estado do Rio de Janeiro (Brasil) entre julho e setembro de 2013 no momento mais oportuno para cada tutor mediante assinatura de concordância a consentimento livre e esclarecido para participação no estudo. 


\section{RESULTADOS E DISCUSSÃO}

\section{Dados pessoais dos tutores}

A análise dos dados pessoais (Tabela 1) revelou que $67 \%$ dos tutores tinham idades entre 30 a 50 anos e a maioria era do sexo masculino (cerca de $83 \%$ ).

Tabela 1.

Dados pessoais

\begin{tabular}{|c|c|c|c|c|c|c|}
\hline \multirow{2}{*}{ Faixa etária } & \multicolumn{7}{|c|}{ Tutores } \\
\cline { 2 - 7 } & I & II & III & IV & V & VI \\
\hline 20 a 30 anos & & & & & & x \\
\hline 30 a 40 anos & & $\mathrm{x}$ & & $\mathrm{x}$ & & \\
\hline 40 a 50 anos & $\mathrm{x}$ & & $\mathrm{x}$ & & & \\
\hline Mais de 50 anos & & & & & $\mathrm{x}$ & \\
\hline Gênero & I & II & III & IV & V & VI \\
\hline Masculino & $\mathrm{x}$ & $\mathrm{x}$ & $\mathrm{x}$ & & $\mathrm{x}$ & $\mathrm{x}$ \\
\hline Feminino & & & & $\mathrm{x}$ & & \\
\hline
\end{tabular}

\section{Dados acadêmicos e experiência dos tutores}

A tabela 2 apresenta os dados acadêmicos dos tutores. Todos possuíam ensino superior completo e curso de capacitação para tutoria a distância. Três (50\%) fizeram graduação na área de humanas - um em administração, um em serviço social e um em filosofia. Dois (33\%) concluíram cursos na área de exatas, um em matemática e outro em análise de sistemas.

Tabela 2.

Dados acadêmicos

\begin{tabular}{|l|c|c|c|c|c|c|}
\hline \multirow{2}{*}{ Área do nível superior } & \multicolumn{7}{|c|}{ Tutores } \\
\cline { 2 - 8 } & I & II & III & IV & V & VI \\
\hline Humanas & & x & $*$ & x & & x \\
\hline Exatas & $\mathrm{x}$ & & $*$ & & $\mathrm{x}$ & \\
\hline Biológicas & & & $*$ & & & \\
\hline Possuía pós-graduação & I & II & III & IV & V & VI \\
\hline Sim & $\mathrm{x}$ & $\mathrm{x}$ & $*$ & $\mathrm{x}$ & $\mathrm{x}$ & $\mathrm{x}$ \\
\hline
\end{tabular}




\begin{tabular}{|l|c|c|c|c|c|c|}
\hline \multirow{2}{*}{ Área do nível superior } & \multicolumn{6}{|c|}{ Tutores } \\
\cline { 2 - 7 } & I & II & III & IV & V & VI \\
\hline Não & & & $*$ & & & \\
\hline $\begin{array}{l}\text { Possuía curso } \\
\text { específico para atuar } \\
\text { na EaD }\end{array}$ & I & II & III & IV & V & VI \\
\hline $\begin{array}{l}\text { Sim } \\
\text { Não }\end{array}$ & $\mathrm{x}$ & $\mathrm{x}$ & $\mathrm{x}$ & $\mathrm{x}$ & $\mathrm{x}$ & $\mathrm{x}$ \\
\cline { 2 - 7 } & & & & & & \\
\hline
\end{tabular}

Nota: * significa não respondeu.

A tabela 3 mostra a experiência na tutoria. Todos trabalhavam em atividades presenciais e semipresenciais, a maioria há menos de 5 anos. Cinco atuavam na modalidade exclusivamente a distância, a maioria entre um e cinco anos.

Tabela 3 .

Experiência na tutoria

\begin{tabular}{|c|c|c|c|c|c|c|}
\hline \multirow{2}{*}{$\begin{array}{c}\text { Tempo de experiência na } \\
\text { modalidade presencial ou } \\
\text { semipresencial }\end{array}$} & \multicolumn{6}{|c|}{ Tutores } \\
\hline & I & II & III & IV & $\mathrm{V}$ & VI \\
\hline \multicolumn{7}{|l|}{ Não atua } \\
\hline \multirow{2}{*}{$\begin{array}{l}\text { Menos de } 1 \text { ano } \\
\text { Entre } 1 \text { e } 5 \text { anos }\end{array}$} & & & & $\mathrm{x}$ & & $\mathrm{x}$ \\
\hline & & $\mathrm{x}$ & $\mathrm{x}$ & & & \\
\hline $\begin{array}{l}\text { Entre } 5 \text { e } 10 \text { anos } \\
\text { aaaanosanos }\end{array}$ & & & & & $\mathrm{x}$ & \\
\hline Mais de 10 anos & $\mathrm{x}$ & & & & & \\
\hline $\begin{array}{l}\text { Tempo de experiência } \\
\text { na modalidade a } \\
\text { distância }\end{array}$ & $\mathbf{I}$ & II & III & IV & $\mathbf{V}$ & VI \\
\hline \multirow{3}{*}{$\begin{array}{l}\text { Não atua } \\
\text { Menos de } 1 \text { ano } \\
\text { Entre } 1 \text { e } 5 \text { anos }\end{array}$} & & $\mathrm{x}$ & & & & \\
\hline & & & & & & $\mathrm{x}$ \\
\hline & $\mathrm{x}$ & & $\mathrm{x}$ & $\mathrm{x}$ & & \\
\hline Entre 5 e 10 anos & & & & & $\mathrm{x}$ & \\
\hline Mais de 10 anos & & & & & & \\
\hline
\end{tabular}




\section{Visão geral das competências socioafetivas: aceitação, cordialidade, empatia e honradez}

Todos os tutores afirmaram ter conhecimento formal das competências socioafetivas, com exceção do tutor IV. Quatro relatam ter adquirido esse conhecimento em curso específico para tutoria e um durante a prática profissional. Apesar de todos terem curso de capacitação, só 67\% aprendeu sobre as competências durante essa formação.

Atabela 4 exibe como os tutores enumeraram as quatro competências socioafetivas em ordem de importância, sendo que a primeira representa a mais importante e a quarta, a menos importante. Entre os tutores, 50\% elegeu a competência socioafetiva cordialidade como a mais importante e 33\%, a aceitação. Somente um tutor (16\%) destacou a honradez. A empatia foi considerada a menos relevante.

Tabela 4 .

Ordem de importância das competências socioafetivas segundo cada tutor

\begin{tabular}{|c|c|c|c|c|c|c|}
\hline \multicolumn{7}{|c|}{ Competências socioafetivas } \\
\hline \multirow{2}{*}{ Ordem } & \multicolumn{6}{|c|}{ Tutores } \\
\hline & I & II & III & IV & V & VI \\
\hline $1^{\mathrm{a}}$ & Cordialidade & Cordialidade & Cordialidade & Honradez & Aceitação & Aceitação \\
\hline $2^{a}$ & Empatia & Aceitação & Aceitação & Aceitação & Honradez & Cordialidade \\
\hline $3^{\mathrm{a}}$ & Honradez & Honradez & Honradez & Empatia & Cordialidade & Empatia \\
\hline $4^{\mathrm{a}}$ & Aceitação & Empatia & Empatia & Cordialidade & Empatia & Honradez \\
\hline
\end{tabular}

Pela média, a capacidade de aceitação e a cordialidade foram escolhidas como as mais importantes. Ao traçar um comparativo entre essas competências contata-se que, embora para os tutores ambas tenham valor semelhante, possuem diferenças em sua aplicação na EaD.

$\mathrm{Na}$ aceitação, a realidade do aluno tem que ser compreendida e aceita de acordo com suas diferenças, tendo como ponto de partida a cumplicidade, a colaboração, a interação e a parceria, indispensáveis na intervenção pedagógica (Oliveira, 2009).

Já a competência socioafetiva cordialidade manifesta-se quando o tutor, um dos elementos fundamentais para o sucesso em um curso de EaD (Bernardino, 2011), atua de forma afável ao interagir com os alunos de forma acolhedora (García Aretio, 1994, p. 335). 


\section{A competência socioafetiva de aceitação}

Na EaD é notória a complexidade das funções e a importância do tutor nas atividades de um ambiente informatizado (Farias, 2010; Giannella, Struchiner e Ricciardi, 2013; Santos, 2013). A competência socioafetiva de aceitação éfundamental nas relações entre aprendentes e ensinantes, pois aceitar e compreender as diferenças e a realidade do aluno é um ponto crucial para o aprendizado a distância (Oliveira, 2009).

A tabela 5 mostra a opinião dos investigados sobre o significado da capacidade de aceitação na tutoria a distância. Todos opinaram corretamente que o significado da aceitação seria compreender a realidade do aluno que, em seus contatos com o tutor, deveria se sentir participante ativo do processo ensinoaprendizagem. Logo, todos conheciam o que seria uma postura de aceitação na tutoria a distância.

Tabela 5 .

Significado da capacidade de aceitação na tutoria a distância

Significado das competências socioafetivas

Aceitar e compreender a realidade do aluno que, em seus contatos com o tutor, deve se sentir participante ativo do processo ensino-aprendizagem

Agir de forma afável, tratar os alunos de modo respeitoso e sensível, demonstrar sinceridade e elogiar mais os acertos que os erros

\begin{tabular}{|l|l}
\hline Perceber o outro e identificar suas necessidades & o
\end{tabular}

Ser humilde na postura com o aluno, além de ser honesto consigo mesmo e com o cursista na certeza de que não existe o detentor absoluto do saber

Tabela 6.

Momentos da tutoria em que a capacidade de aceitação é imprescindível Quando a capacidade de aceitação é imprescindível?

No desenvolvimento do trabalho coletivo, que deve ser pautado no diálogo, no debate, no confronto, na discussão de pontos de vista e, principalmente, no respeito mútuo devido à diversidade cultural

Deve estar presente na hora de receber os alunos no início de cada módulo do curso ao fazer com que se sintam "bem-vindos", respeitados, confortáveis e estimulados a continuar sua caminhada de forma prazerosa, desenvolvendo um clima de autoconfiança

No momento em que o aluno necessite de auxílio para a realização da tarefa, ao perceber a aflição do aluno o tutor pode orientá-lo de maneira que ele consiga o entendimento necessário para a realização da mesma agindo de maneira humana e afetiva 
A tabela 6 exibe alguns momentos da tutoria em um curso de EaD. Cinco tutores (83\%) opinaram que a aceitação é essencial no desenvolvimento do trabalho coletivo. Um (17\%) achava-a necessária ao reconhecer não saber determinado assunto.

Em sua maioria, os tutores levaram em consideração momentos da tutoria em que a capacidade de aceitação é imprescindível, ou seja, no desenvolvimento do trabalho coletivo, que deve ser pautado no diálogo, no debate, no confronto, na discussão de pontos de vista e, principalmente, no respeito mútuo à diversidade.

Algumas situações problemas ocorridas durante a tutoria também foram levadas em consideração. Metade dos tutores elegeu a baixa participação no AVA de toda uma turma como uma situação problemática possível de ser contornada com a aceitação.

Os tutores (33\%) destacaram também a baixa participação no AVA por um cursista em particular, a agressividade entre colegas cursistas e o desestímulo como situações que poderiam ser resolvidas pela aceitação.

Foram aludidas por $16 \%$ dos pesquisados a baixa interação com os colegas e o questionamento à competência técnica do tutor. A dificuldade no processo ensinoaprendizagem, o pouco contato com o tutor e a presunção do cursista não foram citadas.

Nas relações sociais é observável a diversificação cultural e individual entre as pessoas, por isso é importante saber trabalhar de modo que tais diferenças contribuam para o aprendizado e crescimento coletivo, sempre priorizando a aceitação e o respeito mútuo entre os aprendentes (Farias, 2010).

Por isso, os tutores foram questionados em relação à diversidade cultural, social e intelectual no tocante à aprendizagem coletiva. Eles foram unânimes em opinar que a diversidade contribuía para a aprendizagem, não perfazendo de modo algum um empecilho. 
Tabela 7.

Como lidar na tutoria com a diversidade?

\begin{tabular}{|c|c|c|c|c|c|c|}
\hline \multirow{2}{*}{ Como o tutor lida com a diversidade? } & \multicolumn{6}{|c|}{ Tutores } \\
\hline & $\mathrm{I}$ & II & III & IV & V & VI \\
\hline $\begin{array}{l}\text { Busca ser cordial e afetivo, mas evita falar } \\
\text { de si }\end{array}$ & & & $\mathrm{x}$ & & & \\
\hline Compartilha suas experiências pessoais & & & & & $\mathrm{x}$ & \\
\hline $\begin{array}{l}\text { Incentiva os cursistas a compartilharem } \\
\text { suas experiências pessoais }\end{array}$ & & & & & & \\
\hline Estimula a aceitação e o respeito mútuo & $\mathrm{x}$ & $\mathrm{x}$ & $\mathrm{x}$ & $\mathrm{x}$ & $\mathrm{x}$ & $\mathrm{x}$ \\
\hline $\begin{array}{l}\text { Cria estratégias que enfatizem a } \\
\text { diversidade dos cursistas }\end{array}$ & & $\mathrm{x}$ & & $\mathrm{x}$ & & $\mathrm{x}$ \\
\hline $\begin{array}{l}\text { Estimula uma atitude reflexiva e crítica } \\
\text { perante as diferenças }\end{array}$ & & $\mathrm{x}$ & & $\mathrm{x}$ & & $\mathrm{x}$ \\
\hline Evita tarefas que acentuem a diversidade & & & & & & \\
\hline $\begin{array}{l}\text { Pede para os cursistas manterem postura } \\
\text { e linguajar profissionais }\end{array}$ & & & $\mathrm{x}$ & & & \\
\hline
\end{tabular}

A tabela 7 mostra a opinião dos tutores de como lidar na tutoria a distância com a diversidade. Todos concordaram ser de suma importância estimular a aceitação e o respeito mútuo entre os cursistas para favorecer o companheirismo em um grupo diverso. Metade achava o estímulo dos cursistas a uma atitude reflexiva e crítica e à criação de estratégias com ênfase na diversidade boas maneiras de lidar com as diferenças individuais. Um buscava ser cordial e afetivo, além de pedir postura e linguajar profissionais.

A aceitação está presente em todas as relações humanas, mas metade dos tutores concordava haver divergência ou falta de aceitação entre os cursistas esporadicamente. A outra metade, entretanto, achava isso frequente.

As percepções dos tutores sobre a frequência em que há divergência ou falta de aceitação de um cursista em relação ao tutor foram investigadas. A maioria (67\%) mencionou tal comportamento perante o tutor como esporádico. Entretanto, 33\% citaram como comuns essas situações.

Conforme os dados, a falta de aceitação era mais comum na relação cursistacursista do que na cursista-tutor. Isso não se devia necessariamente a um maior apreço à pessoa do tutor, mas sim ao fato dele assumir na $\mathrm{EaD}$, ordinariamente, o papel de avaliador das atividades. 
Apesar disso, muitos ainda apresentavam divergência ou falta de aceitação em relação ao tutor, o que poderia decorrer do baixo reconhecimento da atividade, segundo a visão dos pesquisados.

\section{A competência socioafetiva honradez}

Todos os pesquisados conheciam claramente o significado da competência honradez. Eles julgavam-na indispensável ao reconhecer não saber determinado assunto e a necessidade de pesquisá-lo para debatê-lo com o aluno. Um (Tutor V) citou a honradez como necessária em todos os momentos para o efetivo exercício da tutoria.

Ao apontar situações problemáticas possíveis de serem contornadas com a honradez (Tabela 8), a resposta mais votada foi o questionamento pelo cursista da competência técnica do tutor. Metade citou a agressividade entre os cursistas e a presunção do cursista como prováveis de serem resolvidas com uma postura honrada. A dificuldade na aprendizagem e o pouco contato com o tutor foram mencionados por dois.

A baixa participação de uma turma e de um cursista em particular, a baixa interação entre colegas cursistas e o desestímulo foram aludidos apenas pelo tutor $\mathrm{V}$, que via a honradez como necessária em todos os momentos para o exercício da tutoria.

Tabela 8.

Situação problemática que poderia ser solucionada com a competência honradez

\begin{tabular}{|l|c|}
\hline $\begin{array}{c}\text { Situação problemática passível de solução com } \\
\text { a honradez }\end{array}$ & Total \\
\hline Baixa participação no AVA de toda a turma & 1 \\
\hline $\begin{array}{l}\text { Baixa participação no AVA por um cursista em } \\
\text { particular }\end{array}$ & 1 \\
\hline Agressividade entre colegas de uma disciplina & 3 \\
\hline Baixa interação com os colegas & 1 \\
\hline Desestímulo & 1 \\
\hline Dificuldade no processo ensino-aprendizagem & 2 \\
\hline Pouco contato com o tutor & 2 \\
\hline Presunção do cursista & 3 \\
\hline Questionamento à competência técnica do tutor & 4 \\
\hline
\end{tabular}


Tabela 9 .

O tutor deve reconhecer diante do cursista a dificuldade de responder a uma dúvida?

\begin{tabular}{|l|c|c|c|c|c|c|}
\hline \multirow{2}{*}{$\begin{array}{c}\text { O tutor deve reconhecer a } \\
\text { dificuldade de responder } \\
\text { uma dúvida? }\end{array}$} & \multicolumn{7}{|c|}{ I } & II & III & IV & V & VI \\
${$\cline { 2 - 8 }$} }$ & II & IV & VI & VIII & X & XII \\
\hline Não & & $\mathrm{x}$ & & $\mathrm{x}$ & $\mathrm{x}$ & $\mathrm{x}$ \\
\hline
\end{tabular}

$\mathrm{Na}$ EaD, o tutor é o mediador da aprendizagem (Bernardino, 2011; Farias, 2010). Entretanto, eventualmente, ele pode não ser capaz de responder à dúvida de um cursista. Nessa situação, a maioria considerou que deveria reconhecer para o cursista a sua deficiência em um assunto particular (Tabela 9).

Boa parte dos tutores tentava assumir uma postura honrada em sua atuação, pois admitiam seu desconhecimento, apesar da insegurança de alguns profissionais em revelar ao aluno que ignora determinado assunto por receio de perder a confiabilidade nas demais propostas.

Quando perguntados sobre qual postura o tutor deveria adotar se o cursista perguntasse algo que o mesmo não soubesse, a maioria afirmou que informaria ao aluno a necessidade de pesquisar e dar-lhe-ia a resposta tão logo possível (Tabela 10). Três informariam ao aluno a necessidade de pesquisar, mas não tentariam de fato responder-lhe a dúvida. Um usaria a dúvida como questionamento para os demais cursistas e esperaria que o grupo fornecesse a resposta. Um pesquisaria e responderia apenas quando soubesse a resposta. Alguns selecionaram mais de uma opção e argumentaram que a atitude variaria de acordo com a dúvida.

Tabela 10.

Como o tutor agiria caso um cursista perguntasse algo que ele não soubesse responder?

\begin{tabular}{|l|c|}
\hline $\begin{array}{l}\text { Como o tutor agiria se um cursista perguntasse } \\
\text { algo que ele não soubesse? }\end{array}$ & Total \\
\hline $\begin{array}{l}\text { Não responderia e esperaria a pergunta ser } \\
\text { esquecida }\end{array}$ & o \\
\hline $\begin{array}{l}\text { Orientaria o aluno a pesquisar o assunto, porém } \\
\text { sem ajudá-lo }\end{array}$ & o \\
\hline $\begin{array}{l}\text { Pesquisaria e responderia apenas quando } \\
\text { soubesse a resposta }\end{array}$ & 1 \\
\hline $\begin{array}{l}\text { Informaria ao aluno da necessidade de pesquisar, } \\
\text { mas não tentaria de fato responder-lhe a dúvida }\end{array}$ & 3 \\
\hline
\end{tabular}




\begin{tabular}{|l|c|}
\hline $\begin{array}{l}\text { Como o tutor agiria se um cursista perguntasse } \\
\text { algo que ele não soubesse? }\end{array}$ & Total \\
\hline $\begin{array}{l}\text { Informaria ao aluno da necessidade de pesquisar e } \\
\text { dar-lhe-ia a resposta tão logo possível }\end{array}$ & 5 \\
\hline $\begin{array}{l}\text { Usaria a dúvida como questionamento para } \\
\text { o grupo e esperaria os cursistas fornecerem a } \\
\text { resposta }\end{array}$ & 1 \\
\hline
\end{tabular}

Nota-se a dificuldade de alguns tutores em inserirem-se nos novos paradigmas que envolvem a EaD. Eles apontam na direção de que a leitura de mundo precede a leitura da palavra. O tutor conhece a "leitura da palavra", a teoria, mas o aluno possui sua "leitura de mundo", a prática cotidiana, que não pode ser ignorada. Nesses novos tempos das nTIC em muitas ações diárias (Rosa, 2013), de descobertas científicas regulares, de constantes ressignificações de antigos conceitos, ninguém pode se afirmar como detentor absoluto do saber.

Dessa forma, ao ponderar sobre a competência honradez, acredita-se que a melhor postura seria o tutor reconhecer diante do aluno a necessidade de pesquisar uma resposta para o seu questionamento e respondê-lo tão logo possível. Afinal, o tutor também deve perceber-se responsável pelo processo ensino-aprendizagem do referido aluno e não deixar lacunas de conhecimento.

Um dos questionamentos provocou a reflexão acerca da postura responsável e comprometida do tutor como fator diretamente ligado à confiabilidade do aluno em relação ao curso na modalidade a distância. Todos destacaram o papel fundamental do tutor para gerar a sensação de confiança do aluno.

A opinião dos tutores converge para o apontado na literatura (Bernardino, 2011; Brasil, 2007; Farias, 2010; Preti, 1996), que destaca a tutoria como peremptória para o processo ensino-aprendizagem.

Foi também pedido aos tutores a narrativa de alguma situação problemática que tenham conseguido contornar com o emprego das competências socioafetivas. Entretanto, apenas um quis responder à questão, com a menção: "O aluno postar mensagem da internet como se fosse dele".

A prática de plágio foi apontada como uma ação recorrente dos alunos, em geral, facilitada pela internet. A situação exige da tutoria uma postura honrada. Diante dessa circunstância, a tutoria tem que estar atenta e saber ser ética. O tutor deve ser honesto em seu relacionamento com o cursista, sinalizar para o mesmo sua postura incorreta e solicitar a revisão da atividade. 
A incumbência na postura honrada do tutor também indica o bom senso de fortalecer nos alunos da $\mathrm{EaD}$ a perspectiva de segurança em relação ao curso, na medida em que se propõe uma relação afetiva de honestidade e confiança. Neste contexto, é importante ressaltar as penalidades imposta pela instituição ao comportamento impróprio.

\section{CONSIDERAÇÕES FINAIS}

$\mathrm{O}$ advento das nTICs trouxe mudanças significativas na forma de pensar e agir das pessoas. A informatização passou a nortear as mais simples ações cotidianas. Nessa conjuntura, encontra-se também o processo ensino-aprendizagem. Hoje, as instituições de ensino procuram atender, de forma cada vez mais eficaz, um aluno em busca dos mais variados conhecimentos. A EaD surge como uma possibilidade de suprir algumas problemáticas desse processo tão complexo que é a difusão do conhecimento. O aluno da EaD constrói seu saber por meio da aprendizagem colaborativa a distância. Nela há a combinação dos objetivos pessoais com o coletivo.

$\mathrm{Na}$ atualidade, a educação brasileira vem sofrendo mudanças no que tange a emancipação do estudante e a forma de construção do aprendizado. Hoje, a transmissão do conhecimento (saberes prontos) se coloca em segundo plano e se valoriza a formação de um cidadão pleno, com competências formadas primordialmente para a vida toda.

O grupo atendido em um AVA deve estar unido pelo objetivo de obter uma educação de qualidade, crítica. O principal método para alcançá-la é a aprendizagem colaborativa. Nela, as diferentes habilidades e competências de cada indivíduo devem ser respeitadas, valorizadas e aproveitadas da melhor forma possível.

Essa mudança na área educacional não resulta somente do uso de ferramentas tecnológicas, mas também do fator humano. Em hipótese nenhuma, contudo, se pretende abnegar a importância das nTICs no processo ensinoaprendizagem e seu emprego para uma educação de qualidade. Entretanto, para atender aos requisitos brasileiros técnicos, didáticos e legais (Brasil, 2007), se faz necessário buscar profissionais qualificados para atuar na EaD, atualmente formada por especialistas de diferentes áreas.

Dessa forma, surge a figura do tutor, que por estar diretamente envolvido com o aluno, se constitui em elemento-chave na mediação da transmissão do conhecimento. Esse profissional deve conhecer cada aluno de sua turma e respeitá-lo, agir de forma democrática e ser capaz de envolver todos os cursistas na aprendizagem.

Ao considerar a premissa de que o aluno da EaD necessita de especificidades de tratamento na condução de seu processo ensino-aprendizagem, as competências 
socioafetivas empregadas pelo tutor tornam-se essenciais ao bom desempenho do aluno, ao humanizar as relações entre pessoas que, muitas das vezes, só terão contato por intermédio de um computador (García Aretio, 2002). É preciso investigar as ações necessárias ao tutor para a promoção de uma aprendizagem colaborativa, onde impere com os cursistas um relacionamento de ajuda solidária, pautado na aceitação, cordialidade, empatia e honradez.

O presente estudo qualitativo investigou as percepções de tutores a distância de uma instituição particular de ensino superior no Brasil sobre as práticas educativas relacionadas às competências socioafetivas aceitação e honradez.

Um dos tutores afirmou desconhecer as competências socioafetivas, apesar de todos terem curso de capacitação em tutoria. Além disso, só $67 \%$ aprendeu sobre elas durante essa formação.

Segundo os pesquisados, a ordem decrescente de importância das competências socioafetivas seria: cordialidade, aceitação, honradez e empatia. Todos reconheceram o significado da aceitação e da honradez conforme os preceitos da EaD.

Por unanimidade, os tutores apontaram a honradez como essencial para reconhecer o desconhecimento de determinado assunto. Para a maioria, o questionamento de parte de cursistas quanto a competência técnica do tutor seria uma situação problemática possível de ser solucionada com a honradez. Metade citou também a agressividade e a presunção de cursistas como passíveis de serem contornadas com uma postura honrada.

Grande parte reconheceria para o cursista a deficiência em um assunto particular, caso eventualmente fosse incapaz de responder a uma dúvida. Nessa situação, a maioria informaria ao aluno a necessidade de pesquisar e dar-lhe-ia a resposta tão logo possível. Embora a EaD seja baseada em um papel ativo do aluno, nenhum tutor orientaria o mesmo a pesquisar o assunto, sem ajudá-lo, o que converge com o ensino nesta modalidade. Todos destacaram o tutor como fundamental para suscitar no aluno a sensação de confiança no curso e até no ensino a distância.

Metade elegeu a baixa participação no AVA de toda uma turma como uma situação problema da tutoria que poderia ser revertida com a aceitação. Outras circunstâncias seriam a baixa participação no AVA por um cursista em particular, a agressividade entre colegas e o desestímulo do cursista. Segundo os tutores, era importante estimular a aceitação e o respeito mútuo entre os cursistas para favorecer o companheirismo em um grupo diverso.

Diante das práticas pedagógicas dos pesquisados, percebeu-se que eles tentavam empregar a aceitação em suas atividades, ao observar as diferenças individuais e 
respeitarem e promoverem a diversidade de cada indivíduo. Entretanto, os tutores indicaram não ser incomum a ocorrência de falta de aceitação entre cursistas. Espera-se que essa constatação promova a disseminação do conhecimento sobre as competências socioafetivas não só no âmbito da tutoria.

As competências socioafetivas precisam ser transmitidas também as posturas dos cursistas da EaD, do modo a evitar a agressividade entre colegas e a falta de aceitação e de honradez.

A humanização do ensino a distância depende da competência exercida pelo tutor, mas o cursista também precisa ser parte ativa no processo ensinoaprendizagem.

\section{REFERENCIAS BIBLIOGRÁFICAS}

Andrade, J. B. F. (2007). Mediação na tutoria online: o entrelace que confere significado à aprendizagem. Dissertação de mestrado em tecnologia da comunicação e da informação. Ceará: Universidade Federal do Ceará.

Bernardino, H. S. (2011). A tutoria na EaD: os papéis, as competências e a relevância do tutor. Revista científica de educação a distância, 2(4). Recuperado de http:// revistapaideia.unimesvirtual.com.br/ index.php?journal $=$ paideia\&page $=$ articl e\&op=viewFile\&path[]=166\&path[]=171

Brasil. (2007). Referenciais de qualidade para educação superior a distância. Brasília: Ministério da Educação e Cultura.

Campos, F. C. A., Costa, R. M., e Santos, N. (2007). Fundamentos da educação a distância, mídias e ambientes virtuais. Juiz de Fora: Editar.

Castillo Arredondo, S. (1994). La acción tutorial en la enseñanza a distancia. Trabajo de conclusión de curso de postgrado en educación de personas adultas. Madrid: Instituto universitario de educación a distancia.

Correia, R. L., Santos, J. G. (2013). A importância da Tecnologia da Informação e Comunicação (TIC) na Educação a Distância (EAD) do Ensino
Superior (IES). Revista Aprendizagem em EAD, 2, 1-16.

Coutinho, C. P., Lisbôa, E. S., e Bottentuit Jr., J. B. (2009). Avaliação online através das ferramentas da web 2.o. Revista científica de educação a distância, 2(1). Recuperado de http://revistapaideia. unimesvirtual.com.br/index.php?journa $\underline{\mathrm{l}=\text { paideia\&page }=\text { article\&op }=\text { view\&path }[}$ ]$=79 \&$ path []$=45$

Demo, P. (1996). Educar pela pesquisa. São Paulo: Autores associados.

Farias, E. V. (2010). O tutor na educação a distância: a construção de conhecimentos pela interação nos ambientes midiáticos no contexto da educação libertadora. Revista Scientia FAER, 2(2), 28-37. Recuperado de http://www.faer.edu.br/ revistafaer/artigos/edicao2/elisio.pdf

Farias, S. C. (2013). Os benefícios das tecnologias da informação e comunicação (TIC) no processo de educação a distância (EAD). Revista digital de biblioteconomia e ciência da informação, 11(3), 15-29.

Ferreira, A. L., e Acioly-Régnier, N. M. (2010). Contribuições de Henri Wallon à relação cognição e afetividade na educação. Curitiba: Editora UFPR.

Fiuza, P. J. (2002). Aspectos motivacionais na educação a distância análise 
estratégica e dimensionamento de ações. Dissertação de mestrado em engenharia de produção. Florianópolis: Universidade Federal de Santa Catarina.

Freire, P. (1994). Pedagogia da esperança: um reencontro com a pedagogia do oprimido. 3. ed. São Paulo: Paz e Terra.

Freire, P. (1995). A Educação na cidade. 2. ed. São Paulo: Cortez.

Freire, P. (2005). Pedagogia do Oprimido. 43. ed. Rio de Janeiro: Paz e Terra.

García Aretio, L. (1994). Educación a distancia hoy. Madrid: UNED.

García Aretio, L. (2002). La educación a distancia: de la teoría a la práctica. 2. ed. Barcelona: Ariel.

Giannella, T. R., Struchiner, M., Ricciardi, R. M. (2013). Lições aprendidas em experiências de tutoria a distância: fatores potencializadores e limitantes. Recuperado de http://www. educacaopublica.rj.gov.br/biblioteca/ educacao/0059.html

Laguardia, J., Machado, R., e Coutinho, E. (2010). Interação e comunicação em ambientes virtuais de aprendizado. Revista de ciência da informação, 11(4). Recuperado de http://www.dgz.org.br/ ag010/Art 03.htm

Masetto, M. T., e Behrens, M. A. (2000). Novas tecnologias e mediação pedagógica. Campinas: Papirus.

Moraes, E. E. M. (2011). Repensando o papel do professor e suas práticas pedagógicas em EaD. Trabalho de conclusão de curso de gestão de polos. Rio Grande do Sul: Universidade Federal de Pelotas. Recuperado de http://pt.scribd.com/ doc/57203785/REPENSANDO-OPAPEL-DO-PROFESSOR-TUTOR-ESUAS-PRATICAS-PEDAGOGICAS-EM$\underline{\mathrm{EAD}}$

Neder, M. L. C. (2000). A orientação acadêmica na educação a distância: a perspectiva de (re)significação do processo educacional. Em O. Preti (Org.), Educação a distância: construindo significados, (pp. 1-21). Brasília: Plano.
Nobre, C.V., eMelo, K. S. (2011). Convergência das competências essenciais do mediador pedagógico da EaD. VIII Congresso brasileiro de ensino superior a distância [Anais eletrônicos]. Recuperado de http://pt.scribd.com/doc/94697512/ Convergencias-Das-CompentenciasEssenciais-Do-Mediador-PedagogicoDa-EaD

Oliveira, C. L. A. P. (2009). Afetividade, aprendizagem e tutoria online. Revista Edapeci, 3(3). Recuperado de http:// www.seer.ufs.br/index.php/edapeci/ article/view/565/469

Oliveira, G. M. S. (2008). Concepções de orientadores acadêmicos e estudantes dos cursos de pedagogia a distância da Universidade Federal de Mato Grosso sobre ensino e aprendizagem. Tese de doutorado em Educação. Florianópolis: Universidade Federal de Santa Catarina. Recuperado de https://repositorio.ufsc.br/bitstream/ handle/123456789/91414/261994. pdf?sequence $=1$

Oliveira, S. C. (2006). Inteligência, Afetividade e Aprendizagem. I Encontro nacional de tutores de educação a distância [Anais eletrônicos], 51- 61 . Recuperado de https://docs.google. com $/$ viewer $? \mathrm{a}=\mathrm{v} \&$ pid $=$ sites\&srcid $=$ ZGVmYXVsdGRvbWFpbnxtYXJjZ Wx v Y W $22 \mathrm{ZX} \mathrm{M} \times \mathrm{O} \mathrm{T} \mathrm{c} \mathrm{w} \mathrm{f} \mathrm{G} \mathrm{d} 4$ OjJiOGNjNDZkYjc3NGNhYWI

Perrenoud, P.(1999). Construir competências desde a escola. Porto Alegre: Artmed.

Perrenoud, P. (2000). Novas Competências para Ensinar. Porto Alegre: Artmed.

Preti, O. (1996). Educação a distância: inícios e indícios de um percurso. Cuiabá: NEAD.

Rosa, S. S. (2013). A influência das TDIC na (re)configuração de Modelos de EaD tradicionais para Educação online. RENOTE. Revista de Novas Tecnologias na Educação, 11(3), 1-15.

Santos, M. P. (2013). Tutoria em EaD: um elo de interação entre ensinantes 
e aprendentes virtuais. Revista Paidéi@, 4(7). Recuperado de http:// revistapaideia.unimesvirtual.com.br/ index.php?journal = paideia\&page $=\mathrm{a}$ rticle\&op=viewFile\&path[]=259\&pa th[]=269

Tardif, M. (2002). Saberes docentes $e$ formação profissional. Rio de Janeiro: Vozes.

Venâncio, J. D., e Macedo, A. S. G. (2012). Aprendizagem significativa: pela tutoria humanizadora e humanizada. Recuperado de http://www.educasul. com.br/2012/Anais/Joana.pdf

Xavier, R. T. O., e Silva, J. A. S. (2009). Novos paradigmas nos saberes docentes na Educação a Distância. Revista novas tecnologias na educação, 7(1). Recuperado de http://seer.ufrgs.br/ renote/article/viewFile/13948/7849

\title{
PERFIL ACADÊMICO E PROFISSIONAL DOS AUTORES
}

Noélia Teixeira Mendes. Graduada em Geografia. Especialista em Planejamento, Implementação e Gestão da Educação a Distância, Universidade Federal Fluminense (UFF). Professora da rede pública do município de Queimados, no Rio de Janeiro. Linha de trabalho na área de sistemas de tutorias em cursos a distância.

Norma Alves de Sales Santos. Graduada em Pedagogia e Letras. Especialista em Planejamento, Implementação e Gestão da Educação a Distância, Universidade Federal Fluminense (UFF). Professora da secretaria municipal de educação do Rio de Janeiro. Exerce tutoria a distância pela Fundação Cecierj. Linha de trabalho na área de sistemas de tutorias em cursos a distância.

\section{ENDEREÇO}

\author{
Universidade Federal Fluminense, \\ Rua Mário dos Santos Braga, s/n, \\ Valonguinho, Niterói, CEP: 24020140. \\ Rio de Janeiro, RJ, Brasil.
}

Thaís Tenório. Licenciada em Química. Mestre em Química. Doutora em Química, Pontifícia Universidade Católica do Rio de Janeiro. Linha de trabalho na área de tutoria e dispositivos midiáticos na educação a distância.

E-mail: tenoriocalc@gmail.com

\section{ENDEREÇO}

Pontifícia Universidade Católica, Rua Marquês de São Vicente, 225, Edifício Cardeal Leme, $7^{\circ}$ andar, sala $772 \mathrm{~A}$, Bairro Gávea, CEP: 22453-900, Rio de Janeiro, RJ, Brasil. 
André Tenório. Doutor em Física. Colaborador do Laboratório de Novas Tecnologias da Universidade Federal Fluminense e Professor do Instituto Federal do Rio de Janeiro. Exerce tutoria a distância pela Fundação Cecierj/UFF e UAB/ UFF. Linha de trabalho na área de tutoria e dispositivos midiáticos na educação a distância.

E-mail: tenorioriofrj@gmail.com.

ENDEREÇO

Instituto Federal de Educação, Ciência e Tecnologia do Rio de Janeiro, Rio de Janeiro, RJ, Brasil. Rua Senador Furtado, 121 a 125, Bairro Maracanã, CEP: 20270-021, Rio de Janeiro, RJ, Brasil. Andre Tenorio.

Fechas de recepción del artículo: 17/06/14

Fecha de aceptación del artículo: 25/07/14

\section{Como citar este artículo:}

Teixeira, N., Alves de Sales, N., Tenório, T.; Tenório, A. (2015). As competências socioafetivas aceitação e honradez segundo a percepção de tutores a distância. RIED. Revista Iberoamericana de educación a Distancia, volumen 18, nº 1, pp. 129-149. 